\title{
AVRUPA BİRLİĞİ VE TÜRKİYE KAYNAKLI GIDALARDA 2009-2018 YILLARI ARASINDA RASFF BİLDİIIMLERİ*
}

\author{
Aydın Sağlam, M. Tuğrul Masatcıŏglu ${ }^{\dagger}$ \\ Hatay Mustafa Kemal Üniversitesi, Ziraat Fakültesi, Gıda Mühendisliği Bölümü, Tayfur Sökmen Kampüsü, \\ Antakya, Hatay, Türkiye \\ Geliş / Received: 10.04.2020; Kabul / Accepted: 09.06.2020; Online bask1 / Published online: 22.06.2020
}

Sağlam, A., Masatcıŏlu, M.T. (2020). Avrupa Birliği ve Türkiye kaynaklı gıdalarda 2009-2018 y1lları arasında RASFF bildirimleri. GIDA (2020) 45(4) 623-634 doi: 10.15237/gida.GD20051

Sağlam, A., Masatcooğlu, M.T. (2020). RASFF notification on foods originated from European Union and Turkey between 2009-2018. GIDA (2020) 45(4) 623-634 doi: 10.15237/gida.GD20051

\section{ÖZ}

Bu çalışmanın amacı, Gıda ve Yemler için Hızlı Alarm Sistemi (RASFF) veri kaynağında 2009-2018 yılları arasında gıdalarda yapılan bildirim sayılarını geniş kapsamlı incelemektir. Portalda RASFF üye ülkeleri ile Türkiye kaynaklı gida ve gida ürünlerinden elde edilen veriler; ylllara, ürün kategorilerine, bildirim türlerine, risk kararlarına, bildirim kaynağına ve tehlike kategorilerine göre sınıflandırılmıştır. Ürün kategorisine göre sonuçlar değerlendirildiğinde, en fazla bildirim meyve ve sebzelerde tespit edilmiştir. Bu ürün grubunun; veri kaynağına aktarılan tüm gidalar içerisindeki oranı $\% 20$ olarak saptanmış, Türkiye kaynaklı bildirimi yapılan gıdalar arasındaki payı ise dikkate değer düzeyde (\%62) yüksek bulunmuştur. İlgili süreçte, gıdalarda yapılan bildirimlerde tehlike kategorilerine bakıldığında ilk sırayı mikotoksinlerin aldığı görülmektedir. Mikotoksinler incelendiğinde en fazla bildirimin aflatoksinlerde (\%89) olduğu ve bunu okratoksin A (\%9)'nın takip ettiği belirlenmiştir. Ülkemiz kaynaklı gida bildirimlerinde de benzer bir tablo elde edilmiştir.

Anahtar kelimeler: Gıda ve yemler için hızlı alarm sistemi (RASFF), ürün kategorileri, risk kararları, bildirim türü, bildirim kaynağı, tehlike kategorileri, mikotoksinler

\section{RASFF NOTIFICATION ON FOODS ORIGINATED FROM EUROPEAN UNION AND TURKEY BETWEEN 2009-2018}

\begin{abstract}
The aim of this study is to extensively investigate of the numbers of notifications in foods between 2009 and 2018 by using the Rapid Alert System for Food and Feed (RASFF) data source. In the RASFF portal, food and food products notifications obtained from member countries and Turkey are classified as years, product categories, types of notifications, risk decisions, source of notifications, and hazard categories. When the results are evaluated according to the product category, the most notification was found in fruits and vegetables. The notifications ratio in this category constituted $20 \%$ of total and the notification of fruits and vegetables originated from Turkey were determined remarkably higher (62\%). In this period (2009-2018), it was seen that mycotoxin notifications take the first place according to the hazard category. Once the mycotoxins notifications were examined, it was shown that aflatoxins were the most reported one $(89 \%)$ and it was followed by ochratoxin A $(9 \%)$. A similar trend was also observed in food notifications originated from our country.
\end{abstract}

Keywords: Rapid Alert System for Food and Feed (RASFF), product categories, risk decisions, type of notification, source of notification, hazard categories, mycotoxins

\footnotetext{
* Bu araştırma makalesi Aydın SAĞLAM'ın yüksek lisans tez çalışması kapsamında hazırlanmıştır.

† Yazışmalardan sorumlu yazar / Corresponding author

ब: tmasatci@gmail.com, (D) (+90) 3262455845

冝: (+90) 3262455832
}

Aydın Sağlam; ORCID no: 0000-0003-3721-7783

M. Tuğrul Masatcıoğlu; ORCID no: 0000-0002-2583-8796 


\section{GİRİ̧̧}

Gıda ve Yemler için Hızlı Alarm Sistemi (Rapid Alert System For Food and Feed; RASFF), 1979 yilında kurulan, gidalarda ve yemlerde ciddi riskler oluşmasının sonucunda bu sistemdeki üye ülkelerin (Avrupa Birliği üyesi 28 ülkenin ulusal g1da güvenliği otoriteleri, Avrupa Komisyonu (European Commission; EC), Avrupa Gida Güvenliği Otoritesi (European Food Safety Authority; EFSA), Avrupa Serbest Ticaret Birliği (European Free Trade Association; EFTA) ve Norveç, Lihtenştayn, İzlanda, İsviçre) arasında gıda veya yem ile ilgili sağlık tehditlerine karşı daha hızlı ve koordineli bir şekilde hareket edilmesini ve alınabilecek önlemler ile ilgili yetkili kontrol birimleri arasında bilgi aktarımının yapılabilmesini sağlayan bir araçtır (Anonymous, 2007). Bu sistemde, üye ülkelerden herhangi biri, insan sağlığı açısından gida veya yem kaynaklı olarak tehdit oluşturabilecek bir bilgiyi RASFF aracilığ ile Komisyon'a bildirir. Komisyon irtibat noktas1 tarafindan riskin doğrulanmasından sonra bu bildirimler belirlenen riskin ciddiyetine ve ürünün marketteki dağılımına göre, komisyon irtibat noktası bildirimi ă üyelerine iletmeden önce "alarm", "bilgi" ya da "sınır reddi" bildirimi olarak sinıflandirllır ve RASFF bildirimleri ağda bulunan tüm üyelere iletilir.

RASFF'ın işleyişinin daha net anlaşılabilmesi için Avrupa Birliği Komisyonu tarafindan tanımlanan bildirimlerin açık bir şekilde ifade edilmesi gerekir. Bu bağlamda alarm bildirimleri, markette bulunan gida, yem ya da gidayla temas eden materyal; ciddi bir risk içerdiğinde ve bildirimi yapan ülkeden ziyade başka bir ülkede hızlı hareket etmek gerektiğinde gönderilir. Alarm bildirimi, problem tespit eden ve çekme veya geri çağırmayla ilişkilendirilen bir ölçümü sunan ăg üyesi tarafindan başlatılır ve marketlerinde ilgili ürün bulunan ağ üyelerinin tamamına bildirimi doğrulamak için gerekli bilgi vermeyi amaçlar. Alarm bildirimine maruz kalan ürünler çekilmiş ya da marketlerden çekilmek üzere işlenenlerdir. Üye ülkelerin eğer gerekliyse medyaya detaylı bilgi sağlamayı içeren eylemleri gerçekleştirecekleri kendi mekanizmaları vardır. Sınır reddi bildirimleri; insan sağlığı ve hayvan sağllğı için risk oluşturmasından dolayı Avrupa Birliğ̣’’ne girişte reddedilen gida, yem ya da gidayla temas eden materyaller gibi sevkiyatlarla ilgili bildirimlerdir. Bilgi bildirimleri, riski tespit edilmiş gıda, yem ya da gidayla temas eden materyalle ilgili ciddi bir risk durumu olmaması veya bildirimin yapıldığ zamanda ürünün marketlerde bulunmamasindan dolayı hizlı hareket etmeyi gerektiren bir durum olmadığında gönderilir. Avrupa Birliği Komisyonunun 16/2011 sayll düzenlemesi 2 çeşit bilgi bildirimi tanımlar (EC, 2011). Bunlardan ilki olan takip için bilgi bildirimleri; başka üye ülkelerin marketlerinde yer alabilen ürünlerle ilgilidir. Dikkat için bilgi bildirimleri ise; sadece bildirim yapan ülkede bulunan ürünler, henüz marketlerde bulunmayan ürünler veya artık marketlerde olmayan ürünler için gönderilir. RASFF haberleri, gida veya yem güvenliği ile ilgili bir alarm, bilgi veya sınır reddi bildirimi olarak iletilmeyen ancak üye ülkelerdeki gida ve yem kontrol yetkilileri için kayda değer olarak değerlendirilen herhangi bir bilgi türüyle ilgilidir (Anonymous, 2017).

RASFF'ın risk-fayda değerlendirmesi için farklı görüssler ileri sürülmüştür. Bánáti (2011) RASFF'ın yararlı bir araç olduğunu, ancak kontamine gidaların piyasadaki gida zincirine girmesini engelleyemeyeceğini bildirmiştir. Trevisani ve Rosmini (2008) RASFF uyarılarının, gıdaları geri çağırmak veya ithal gıda ve ürünlerin piyasaya sürülmeden önce derecelendirme riskleri için faydalı olacağını rapor etmişlerdir. Diğer taraftan, Marvin vd. (2009) RASFF sistemi içerisinde tehlikelerin ancak meydana geldikten sonra tespit edildiğini; bu nedenle, herhangi bir müdahale için etkin olmayacağını bildirmişlerdir. Spichtinger ve Astley (2009) ise, RASFF'n Avrupa'da gida güvenliğinin sağlanmasında hayati bir rol oynadığını ve tüketiciler için proaktif bir yaklaşım sergilediğini belirtmektedir.

Pigłowski (2020) tarafindan yapılan araştırmada 1979-2017 y1llar1 arasinda, gidanin RASFF sisteminde en s1k bildirilen (tüm bildirimlerin \% 89.5 ’i) ürün türü olduğu rapor edilmiştir. Aynı araştırmada, gıdalarda tehlike kategorisine göre en çok RASFF bildirimi mikotoksinlerde (g1da içindeki bildirimlerin \% 23.0'1) tespit edilmiştir. Bunlar1 sirasıyla, patojen mikroorganizmalar ( $\%$ 
18.2), pestisit kalıntıları (\% 8.7), ağır metaller ( $\%$ 6.0), bileşim (\% 5.8), gida katk1 maddeleri ve aroma maddeleri (\% 5.6), veteriner tıbbi ürün kalıntıları (\% 4.4) ve yabancı cisimler (\% 3.7) takip etmektedir.

Kowalska vd. (2018) Polonya'daki tahıl ve firıncilık ürünlerinde yapılan gida hilelerini araştırdıkları çalışmalarında, Polonya ile bağlantılı RASFF portalinda yer alan tahil ve firincilık ürünlerinde genel bildirimleri ( $\mathrm{n}=177$ ) inceleyerek en çok uyumsuzluğun mikotoksinler, beyan edilmemiş genetik modifiye materyaller ve alerjenler üzerine olduğunu rapor etmişlerdir. Pop vd. (2015) araştırmalarında 2007-2014 y1ları arasında RASFF yıllık raporlarını baz alarak gida ve yemlerde tanımlanan biyolojik tehlikelerin düzeyini analiz etmişlerdir. Anılan çalışmada Avrupa Ekonomik Alanı (European Economic Area, EEA) ülkeleri tarafından mikotoksin kontaminasyonları (aflatoksin; AF, deoksinivalenol; DON, fumonisin; F, okratoksin A; OTA, patulin, zearalenon; ZEN) dikkate alınarak gönderilen bildirimlerden alınan bilgilerin analizine başvurulmuştur. Çalışma bulguları, mikotoksin kontaminasyonun (AF baskın olmak üzere) görülme sıkllğının önemli düzeyde olduğunu ve fakat son yıllarda mikotoksin kontaminasyonlarının azalma trendi (2007-2014 yılları arasinda $\% 50$ civarında) gösterdikleri bildirilmiştir. $\mathrm{Bu}$ gelişimin RASFF sisteminin kullanışlılık ve verimliliğinin yansıması olarak göz önüne alınabileceği vurgulanmıştır. Çınar vd. (2017) 2009-2016 yıllarını kapsayan RASFF Türkiye raporunda, söz konusu yıllarda Avrupa Birliği'ne yapılan ihracatların ülkemiz kayaklı temel sorunun ürünlerdeki yüksek aflatoksin düzeyi olduğunu bildirmişlerdir.

Bu çalışmanın öncelikli amacı, 2009-2018 yıllarını kapsayan on yllik periyotta RASFF (Gida ve Yemler için Hızlı Alarm Sistemi)'a üye ülkelerde gida ve gida ürünlerinde gerçekleşen bildirimlerin yllara, ürün kategorilerine, bildirim türlerine, risk kararlarına, bildirim kaynağına ve tehlike kategorilerine göre sinıflandırılıp, detaylı olarak incelenmesi ve bu süreçte ülkemiz kaynaklı gidalarda yapılan bildirimler ile kıyaslanmasıdır. Çalışmada ayrıca, gidalarda en ciddi tehlike oluşturan bildirim türü olan mikotoksinler kapsamlı olarak ele alınmıştır.

\section{MATERYAL VE YÖNTEM \\ Veri Materyali}

$\mathrm{Bu}$ çalışmada RASFF veri tabanı (https://webgate.ec.europa.eu/rasff-window/ portal/) kaynak olarak kullanılmıştır (RASFF Portal, 2019). RASFF portalında primer arama tipi "g1da" olarak seçilmiştir. Bildirim türleri; alarm, sınır reddi, bilgi bildirimi, takip için bilgi bildirimi, dikkat için bilgi bildirimi olarak sınıflandırılmıştır. Çalışmada bildirim kaynakları; sınır kontrolü (sevkiyatı engellenmiş, sevkiyatına izin verilmiş veya gümrük sevkiyatı), şirketin kendi ürünlerine yaptığ1 kontroller, tüketici şikâyeti üzerine yapilan kontroller, gida zehirlenmeleri üzerine yapilan kontroller, medya takibi, RASFF bildirimlerinin ardindan resmi kontroller, piyasadaki resmi kontroller ve ACC üzerinden istek/bilgi şeklinde gruplandırılmışır. Gıda bildirimlerinin RASFF portalında tehlike kategorileri; hile, alerjenler, biyolojik kontaminantlar, kimyasal kontaminantlar, bileşim, çevresel kirleticiler, gida katk1 maddeleri ve aromalar, yabanc1 maddeler, genetiği değiştirilmiş g1da, endüstriyel kontaminantlar, etiketsiz veya eksik/yanlış etiketleme, metaller, mikrobiyal kontaminantlar, migrasyon, mikotoksinler, doğal toksinler, diğer/belirlenmemiş, yeni geliştirilen g1da, organoleptik görünüm, hatalı/yanlış paketleme, parazit istilas1, patojenik mikroorganizmalar, pestisit kalıntıs1, yetersiz kontrol, proses kontaminantlar1, radyasyon, veterinerlik tıbbi ürün atıkları ve TSEs (örneğin; geviş getiren hayvan DNA varlığı olarak sınıflandırılmıştır. Tehlike kategorisinde risk kararları ise ciddi, ciddi değil ve kararsız olmak üzere 3 grup altında değerlendirilmiştir. RASFF portalı ürün kategorisinde tüm gidalar (örneğin; tahıl ve firıncılık ürünleri, süt ve süt ürünleri, et ve et ürünleri, meyve ve sebzeler, balık ve balık ürünleri) araştırma kapsamında incelenmiştir. Çalışmada RASFF sistemine üye tüm ülkelerden gelen bildirimler dikkate alınmıştır. Ayrıca, ülkemiz kaynaklı gıdalarda yapılan bildirimlerin değerlendirilmesi amaciyla portalda ürün kategorisi altında ülke sekmesinden Türkiye seçilerek tarama yapılmıştır. 


\section{Verilerin Değerlendirilmesi}

RASFF portalında 01 Ocak 2009 - 31 Aralık 2018 tarihleri arasında, RASFF üyelerinin yaptıkları ve Türkiye kaynaklı bildirimler Microsoft Excel (2016) programı kullanılarak değerlendirilmiştir. Elde edilen veriler bildirimlerin yapıldığı yıllara, bildirimleri yayınlayan ülkelere, bildirim türlerine, gida ürünü türlerine, tehlikenin çeşitlerine, risk değerlendirmelerine ve kontrol noktalarına göre sınıflandırılmıştır. Türkiye kaynaklı gıdalarda yapılan bildirim sayıları ile RASFF üyesi ülkeler tarafindan yapılan bildirim sayılarını kıyaslamak amaciyla SPSS paket programı kullanilarak korelasyon katsayıları hesaplanmıştır.

\section{BULGULAR VE TARTIŞMA}

Gıda ve Yemler için Hızlı Alarm Sistemi (Rapid Alert System For Food and Feed; RASFF) portalında RASFF üyesi ülkeler ve Türkiye kaynaklı gidalarda (ham ve/veya işlenmiş) 2009_ 2018 arasında yapılmış olan bildirimlerin yillara göre dağılımı Şekil 1'de verilmiştir. RASFF üyesi ülkeler tarafindan son on yilda gidalarda toplam 28493 bildirim yapıldığı, bu bildirimlerin 2009'dan 2011'e kadar artış gösterdiği ve 2011 yllından da 2014'e kadar azalma eğiliminde olduğu tespit edilmiştir. Ayrıca, RASFF bildirimlerinin yaklaşık $\% 30$ artsşla son 2 yilda en yüksek seviyelere ulaştığ1 saptanmıştır (Şekil 1). Pigłowski (2020) araştırmasında, tehlike kategorilerini dikkate alarak 2000-2017 y1lar1 arasinda RASFF portalında toplam bildirim sayılarını incelemiş, 2002/2003'ten 2005/2006'ya kadar bildirim sayısında önemli bir artış olduğunu ve daha sonraki süreçte sayının stabil devam ettiğini; bununla birlikte, 2017 yılında yine önemli bir artış meydana geldiğini bildirmiştir. Çalışmada, 20002017 yıllarındaki gıda akışı ile RASFF sistemindeki bildiri sayıs1 arasında orta düzeyde korelasyon (Pearson katsayıs1, $r$ ) tespit edilmiştir. Araştırmacı, burada önemli olan etkenin, Avrupa Birliği içi ithalat durumunda elde edilen korelasyonun $(r=$ 0.69), Avrupa Birliği dışı ithalat durumundan $(r=$ 0.53) daha yüksek, bunun da iç pazardan gelen gida miktarı ile ilgili tehlikelerin tespitinin daha yüksek olmasıyla ile ilişkili olduğunu rapor etmiştir.

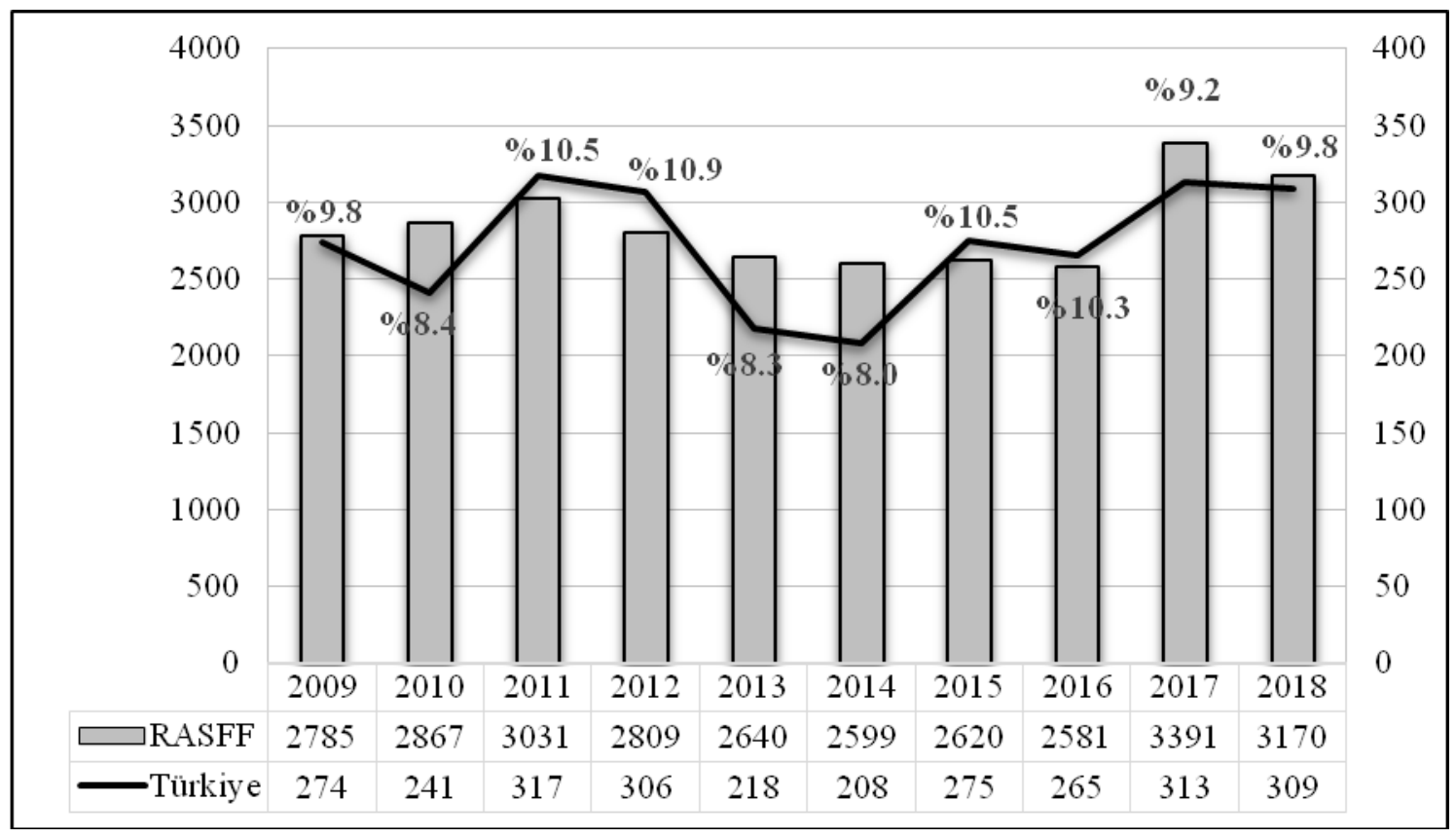

Şekil 1. G1dalarda 2009-2018 yılları arasında yapılan RASFF bildirim sayılanı

Figure 1. RASFF notifications in foods between 2009-2018 
Türkiye kaynaklı gıdalarda yapılan bildirim sayıları ile RASFF üyesi ülkeler tarafından yapılan bildirim sayıları arasında yüksek düzeyde korelasyon $(r=$ 0.71) belirlenmiştir. Şekil 1'de ayrıca ülkemiz kaynaklı gıdalarda yapılan bildirimlerin, RASFF sistemindeki toplam bildirimlere oranlar1 da verilmiştir. Buna göre, toplam bildirimlerin \%8.0$\% 10.5$ 'inin ülkemiz kaynaklı olduğu tespit edilmiştir.

RASFF portalında ürün kategorilerine göre bildirim sayıları incelendiğinde; en fazla bildirim meyve ve sebzelerde (\%20) olurken; bunu \%17'lik oranla sert kabuklu yemişler ve tohumlar takip etmektedir. Tahıl ve firnncilık ürünlerinde ise bildirim sayısı yaklaşı \%5 oranında (1446 bildirim) tespit edilmiştir. Türkiye kaynaklı g1dalarda 2009-2018 y1lar1 arasında ürün kategorilerine göre bildirim sayısına bakıldığında en fazla bildirim meyve ve sebzelerde (\%62) olurken; bunu \%27'lik oranla sert kabuklu yemişler ve tohumlar takip etmektedir. Tahil ve firıncılık ürünlerinde ise bildirim sayısı yaklaşık $\% 1$ oranında tespit edilmiştir. Türkiye kaynaklı gıdalarda ürün kategorilerine göre bildirim sayıları, RASFF ağındaki üye ülkelerden alınan veriler ile kıyaslandığında oransal bir farklilık gösterse de sıralamanın aynı olduğu görülmektedir. Çınar vd. (2017) Türkiye tarafından ihraç edilen ve RASFF veri tabanında (2009-2016) en çok bildirimi bulunan ürün grubunun meyve ve sebze $(\% 60)$ olduğunu rapor etmişlerdir. Bir diğer çalışmada, 2011-2015 yılları arasında ülkemiz kaynaklı ürün gruplarına göre bildirim sayısı incelenmiş, en fazla bildirimin \%64 ile meyve ve sebzeler için olduğu ve bunu $\% 23$ ile sert kabuklu yemişler ve tohumların takip ettiği bildirilmiştir (Yılmaz Çebi ve Olhan, 2017).

RASFF portalında g1da ürünlerinde 2009-2018 yılları arasında yapılan bildirimlerin türlere göre (alarm, sınır reddi, bilgi bildirimi, takip için bilgi bildirimi, dikkat için bilgi bildirimi) değişimi Şekil 2'de sunulmuştur. RASFF sisteminde 2009 ve 2010 yıllarında alarm, sinır reddi ve bilgi bildirimleri yapılmışken, 2011 yllından itibaren "bilgi" bildirimleri yerine "dikkat için bilgi" ve "takip için bilgi" bildirimleri yapılmıştır. Son on yılda bildirimlerin türlere göre dağllımı incelendiğinde sınır reddi bildirimleri \%46'llk oranla en yüksek değere sahip bulunmuştur. RASFF portalında 2009-2018 y1lları arasinda gidalarda 6515 alarm bildirimi, 13062 sinır reddi bildirimi, 1959 bilgi bildirimi, 4387 dikkat için bilgi bildirimi ve 2570 takip için bilgi bildirimi yapılmıştır (Şekil 2a). Türkiye kaynaklı gıdalarda 2009-2018 ylları arasinda toplamda 2726 RASFF bildirimi yapılmış olup, bu bildirimlerin \%7'si alarm bildirimi (186 bildirim), \%80'i sınır reddi bildirimi (2180 bildirim), \%4'ü bilgi bildirimi (118 bildirim), \%7'si dikkat için bilgi bildirimi (193 bildirim), \%2'si takip için bilgi bildirimi (49 bildirim) olarak tespit edilmiştir (Şekil 2b). Dolayısıyla, Türkiye kaynaklı gidalarda türlere göre en fazla bildirimin sınır reddi bildirimleri olduğu, bir diğer ifadeyle ihraç edilen gidaların daha pazara girmeden sinırda ret edildiği görülmektedir. Yılmaz Çebi ve Olhan (2017) çalışmalarında, sınırdan geri çevrilen gıdaların ülkemize ulaştığında, "Bitkisel Gida ve Yemin İhracatında Sağlık Sertifikası Düzenlenmesi ve İhracattan Geri Dönen Ürünler İçin Uygulama Yönetmeliği" (Anonymous, 2011) kapsamında işlem gördügünü bildirmişlerdir. Öte yandan bu durum, ülkemiz ihracatını da önemli düzeyde etkilemekte ve gıda güvenliği konusunda ihracatçı ülkeler tarafından endişe yaratmaktadır.

RASFF bildirimlerinde alınan risk kararları ciddi, ciddi değil ve kararsı olmak üzere 3 gruba ayrilmaktadır. RASFF portalında 2009-2011 yıllarında alınan risk kararları "kararsız" şeklinde bildirilmiş olup; 2011 yllından sonra alınan risk kararlarında "kararsız" bildirimler azalma eğilimi göstermiş, "ciddi" risk kararlarında ise, artış gözlemlenmiştir. Son on yllda (2009-2018) yapilan 28493 bildirimin \%45'i kararsiz (12682 bildirim), \%41'i ciddi (11678 bildirim), \%14’ü ciddi değil (4133 bildirim) risk kararı şeklinde dağılım göstermiştir. Türkiye kaynaklı bildirimlerin risk kararları ise, \%46's1 ciddi (1250 bildirim), \%43’ü kararsiz (1172 bildirim), \%11'i ise ciddi değil (304 bildirim) düzeyinde tespit edilmiştir.

RASFF portalına ilgili süreçte bildirim yapan ülkeler arasinda 4086 bildirim ile (toplam bildirimin \%14'ü) İtalya ilk sirada yer alırken, 
bunu sirasıyla Büyük Britanya (3268 bildirim; $\% 12$ ) ve Almanya (3106 bildirim; \%11) takip etmektedir. Türkiye kaynaklı gidalarda 2009-2018 yılları arasında en çok bildirim yapan ülke 605 bildirim ile (toplam bildirimin \%22'si) Bulgaristan olurken, Bulgaristan'1 sirasiyla, Almanya (549 bildirim; \%20), Fransa (287 bildirim; \%11) ve İtalya (260 bildirim; \%10) takip etmektedir. Avrupa Birliği'ne meyve ve sebze ihracatımızın yaklaşı \%90'1 lojistik bakımdan tercih edilen
Bulgaristan üzerinden yapılan resmi kontrollerden sonra üye ülke pazarına sunulmaktadır (Yılmaz Çebi ve Olhan, 2017). Diğer taraftan, Türkiye'nin 2008'den 2017 y1lı sonuna kadar toplamda 1.388.195.824 \$ ihracat yaptığ1 ve buradaki en büyük payın Almanya'ya ait olduğu bildirilmiştir (Koşar, 2018). Bu literatür bilgileri, Türkiye kaynaklı gıdalarda en çok bildirim yapan ülkeleri destekler niteliktedir.
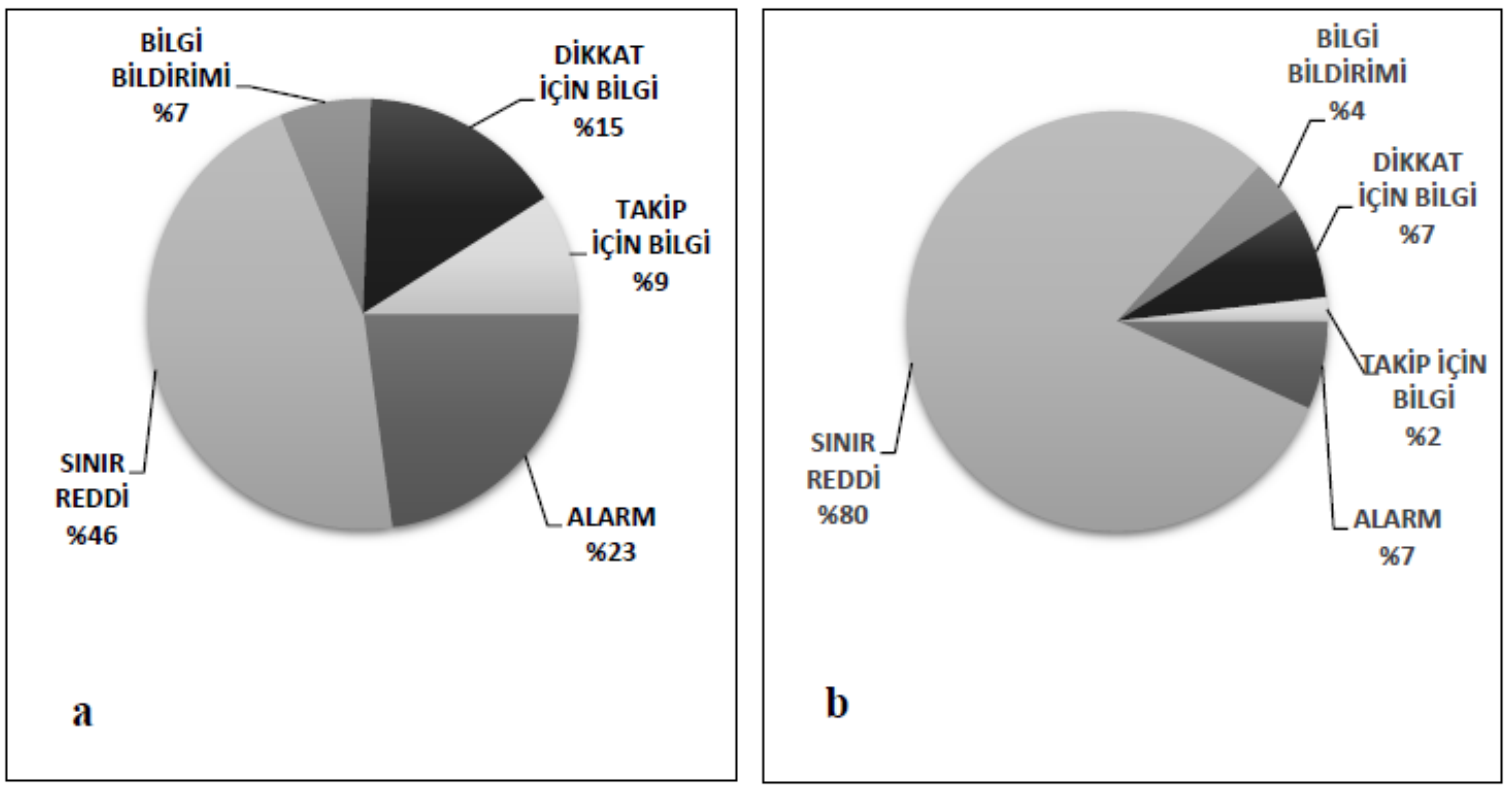

Şekil 2. Gıdalarda 2009-2018 yılları arasında yapılan RASFF bildirim türleri; (a) RASFF ve (b) Türkiye kaynaklı veriler

Figure 2. RASFF notification types in foods between 2009-2018; according the source of (a) RASFF and (b) Turkey

G1dalarda bildirim kaynağına göre 2009-2018 yılları arasinda yapilan RASFF bildirimlerin \%51’i sınır kontrolü, \%30’u piyasadaki resmi kontrolleri, $\% 11$ 'i şirketin kendi ürünlerine yaptı̆g kontroller, \%4’ü tüketici şikâyeti üzerine yapılan kontroller, $\% 2$ 'si g1da zehirlenmeleri üzerine yapilan kontrolleri kapsarken, diğerleri ise \%1'lik dilimi kapsamaktadır. Türkiye kaynaklı gıdalarda ise ilgili süreçte (2009-2018) yapılan bildirimlerin \%82'si sınır kontrolü, \%14’ü piyasadaki resmi kontrolleri kapsarken, \%4'lük dilimi ise diğerleri oluşturmaktadır. Son on yılda Türkiye kaynaklı 2726 bildirimin 2027'si sinurda kontrol edilip sevkiyatına izin verilmeyen gidalar oluşturmaktadır.
Gidalarda bildirimlerin tehlike kategorilerine göre 2009-2018 yilları arasında yapılan RASFF bildirim sayıs1 Şekil 3'te sunulmuştur. Son on yilda g1dalarda tehlike kategorisine göre en çok RASFF bildirimi mikotoksinlerde (5137 bildirim; toplam bildirimin \%17'si) yapılmışır. Bunları sırasıyla patojen mikroorganizmalar (4218 bildirim; \%14), pestisit kalıntıları (3380 bildirim; \%12) ve diğerleri takip etmektedir. RASFF sisteminin kurulduğu 1979 yll ile 2017 yıllarını kapsayan bir araştırmada, tehlike kategorilerine göre yapılan toplam 45761 bildirimin 10507'sini (\%23) mikotoksinlerin oluşturduğu ve bunu sırasıyla patojen mikroorganizmalar (8322 bildirim; $\% 18.2$ ) ve pestisit kalıntlarının (4002 bildirim; 
\%8.7) izlediği bildirilmiştir (Pigłowski, 2020). Bu bilgi göz önüne alındığında RASFF sisteminin kurulduğu günden bu yana mikotoksinlerde yapılan toplam bildirim sayısının yaklaşı yarısının son on y1llık dönemde olduğu görülmektedir. Türkiye kaynaklı gidalarda tehlike kategorisine göre mevcut durum değerlendirildiğinde, ilgili periyotta en fazla bildirimin (1364 bildirim) mikotoksinlerde yapıldığı tespit edilmiştir. Bu değer, RASFF üye ülkeleri tarafindan bildirilen toplam mikotoksin değerinin \%26.6'sını kapsamaktadır. Bir diğer anlatımla, RASFF portalında gidalarda yapilan toplam mikotoksin bildirimlerinin \%26.6'sını Türkiye kaynaklı gıdalar oluşturmaktadır. RASFF portalından elde edilen veriler değerlendirildiğinde; en çok bildirimin mikotoksinler kategorisinde olması dikkat çekici bulunmuş, makalenin ilerleyen bölümünde RASFF portalında mikotoksin başlı̆̆ daha detaylı incelenmiştir.

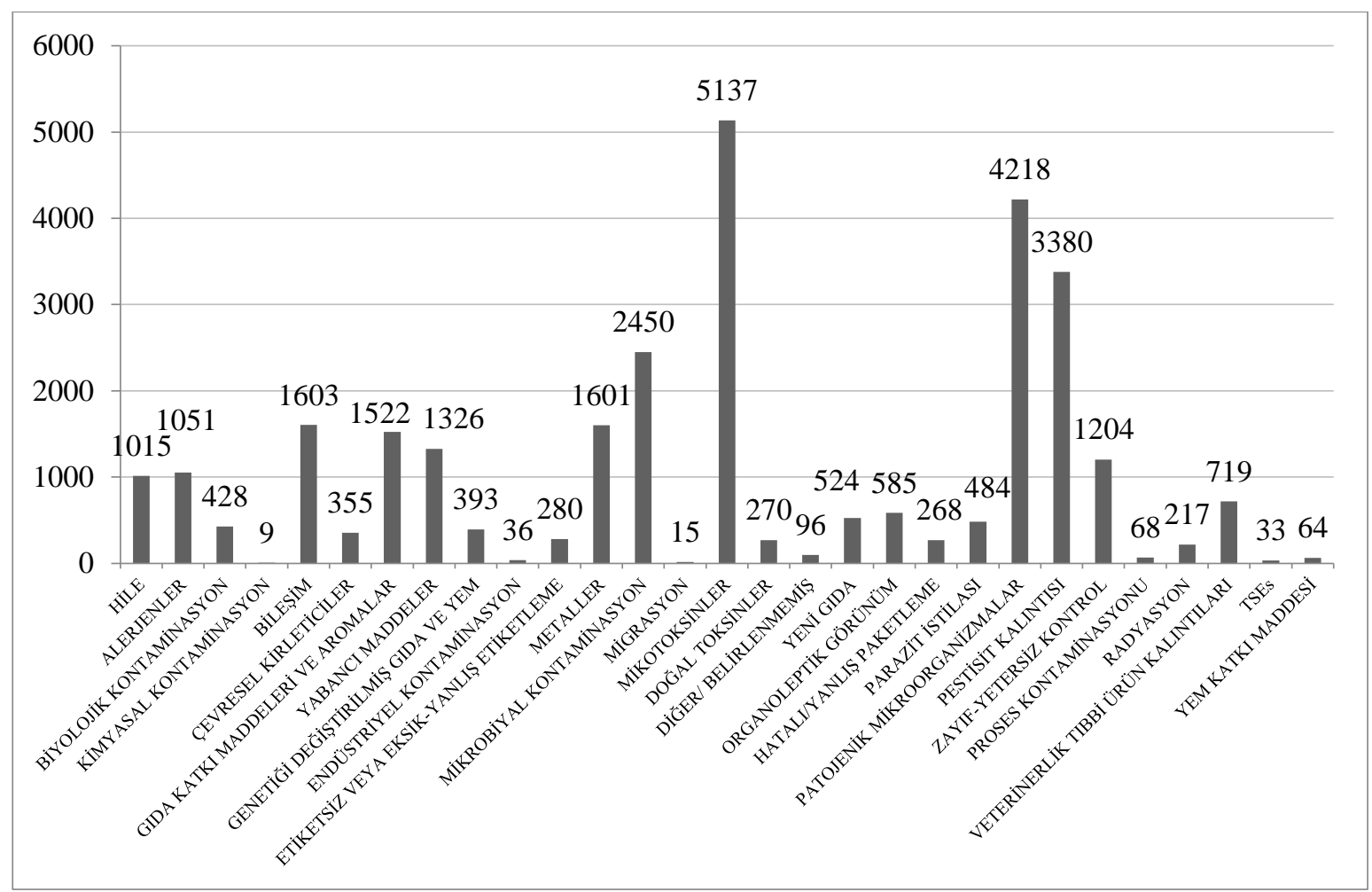

Şekil 3. Gıdalarda bildirimlerin tehlike kategorilerine göre 2009-2018 yılları arasında yapılan RASFF bildirim sayis1

Figure 3. RASFF notifications between 2009-2018 according to the hazard categories of notifications in foods

Gıdalarda Tehlike Kategorisine Göre Mikotoksinlerde Yapılan RASFF Bildirimleri RASFF portalinda son on y1lda (2009-2018 yllar1 aras1) gidalarda tespit edilen mikotoksin bildirimlerinin yıllara göre değişimi Şekil 4'te sunulmuştur. En yüksek mikotoksin bildirimi 2010 yllında tespit edilirken, 2010 yllindan 2014 yllına kadar dikkate değer bir azalma tespit edilmiştir. 2014 yllından 31 Aralık 2018 tarihine kadar mikotoksin miktarında ise ciddi artış görülmüştür. Türkiye kaynaklı gıdalarda tespit edilen mikotoksinlerde 2009 yllında maksimum seviyede olan bildirim sayis1 2014 y1linda minimum düzeye inmiştir. 2015 yllından itibaren bildirim sayılarında bir önceki yıla göre artış gözlenmiştir (Şekil 4). Türkiye kaynaklı gıdalarda tespit edilen mikotoksinler için RASFF bildirimlerindeki bu genel eğilim üye ülkelerin verileri ile orta düzeyde korelasyon $(r=0.45)$ göstermiş olsa da, toplam mikotoksin bildirimin \%17.2-37.7'sinin Türkiye kaynaklı olduğu tespit edilmiştir. Pop vd. (2015) RASFF yıllık raporlarını 
baz alarak 2007-2014 y1lar1 arasinda gida ve yemlerde mikotoksin kontaminasyonun (AF baskın olmak üzere) görülme sıklı̆̆ının önemli düzeyde olduğunu ve fakat çalışmanın kapsadığ1 son yillarda mikotoksin kontaminasyonlarının azalma eğilimi (yaklaşı \%50 civarında) gösterdiğini rapor etmişlerdir. Elde edilen veriler literatür ile benzerlik göstermektedir.

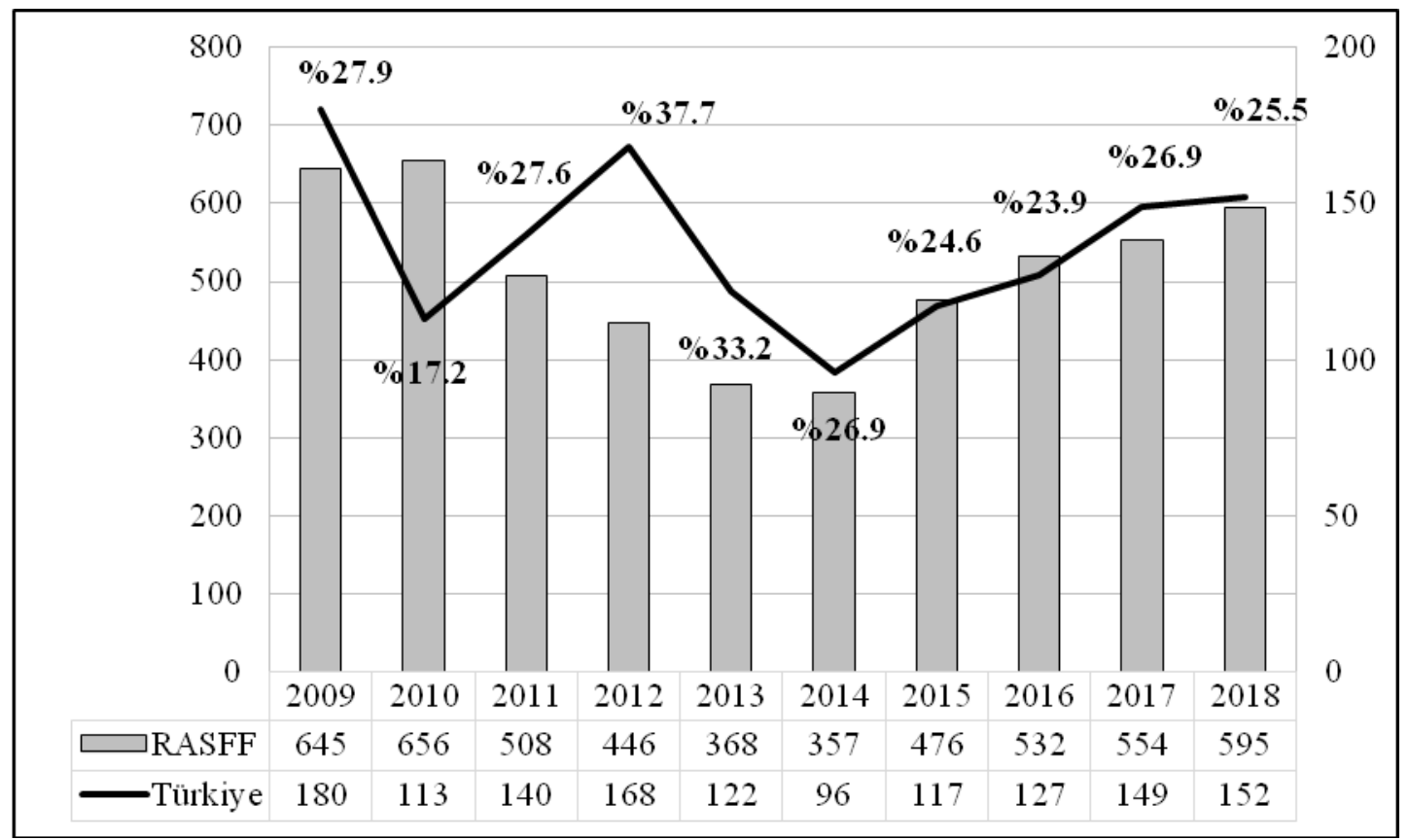

Şekil 4. Gıdalarda tespit edilen mikotoksinlerde 2009-2018 yılları arasında yapılan RASFF bildirim say1s1

Figure 4. RASFF notifications between 2009-2018 on mycotoxins detected in foods

Yapılan bu mikotoksin bildirimlerinden 4076's1 sınır reddi bildirimi, 615'i alarm bildirimi, 108'i bilgi bildirimi, 315'i dikkat için bilgi bildirimi ve 23 'ü ise takip için bilgi bildirimi olarak belirlenmiştir. İncelenen periyotta (2009-2018) tespit edilen toplam 5137 mikotoksin bildiriminin \%40'1 (2064 bildirim) "kararsiz", \%59'u (3045 bildirim) "ciddi", \%1'i (28 bildirim) ise "ciddi değil" risk kararı şeklindedir. Gıdalarda tespit edilen mikotoksinler bildirim kaynağına göre incelendiğinde; \%82'si sinır kontrolü, \%14’ü piyasadaki resmi kontrolleri kapsarken, diğerleri ise \%4'lük paya sahiptir. İlgili süreçte Türkiye kaynaklı gidalarda tespit edilen mikotoksinlerde toplamda 1364 bildirim yapılmıştır. Bu bildirimlerin 1153'ü sinır reddi bildirimi, 105'i alarm bildirimi, 27'si bilgi bildirimi, 76's1 dikkat için bilgi bildirimi ve 3'ü takip için bilgi bildirimidir. $\mathrm{Bu}$ bildirimlerin 858 ' $\mathrm{i}$ ciddi risk kararında, 4'ü ciddi değil ve 502'si kararsı olarak ele alınmıştır. Türkiye kaynaklı gidalarda tespit edilen mikotoksinlerin 2009-2018 y1llar1 arasinda yapılan bildirimlerin \%86's1 sinır kontrolü, \%12'si piyasadaki resmi kontrollerini kapsarken, diğerleri ise \%2'lik dilimi kapsamaktadır. Bu bağlamda hem RASFF üye ülkeleri hem de ülkemizde en fazla bildirimi; sınırda kontrolü sağlanıp sevkiyatına izin verilmeyen mikotoksin kaynaklı gıdalar oluşturmaktadır.

RASFF portalinda elde edilen bulgular değerlendirildiğinde, son on yllda mikotoksin bildirimlerinin \%89'unu aflatoksin (AF), \%9'unu okratoksin A (OTA) ve \%2'lik kısmını diğer mikotoksinlerin oluşturduğu görülmektedir. Gidalarda 2009-2018 yillar1 arasinda RASFF sisteminde yapılan AF ve OTA bildirimlerinin yıllara göre dağılımı Şekil 5'te gösterilmiştir. Buna göre AF bildirim sayıs 2010 yılindan 2014 yllina kadar düşüş gösterirken, takip eden yıldan itibaren 
AF bildirim sayılarında tekrar bir artış gözlemlenmiştir. Şekil 4 ve Şekil 5'te gözlenen bu eğilim 2014 yllında yürürlüğe giren Avrupa Birliği Komisyonu Yönetmeliği ile açıklanabilir.

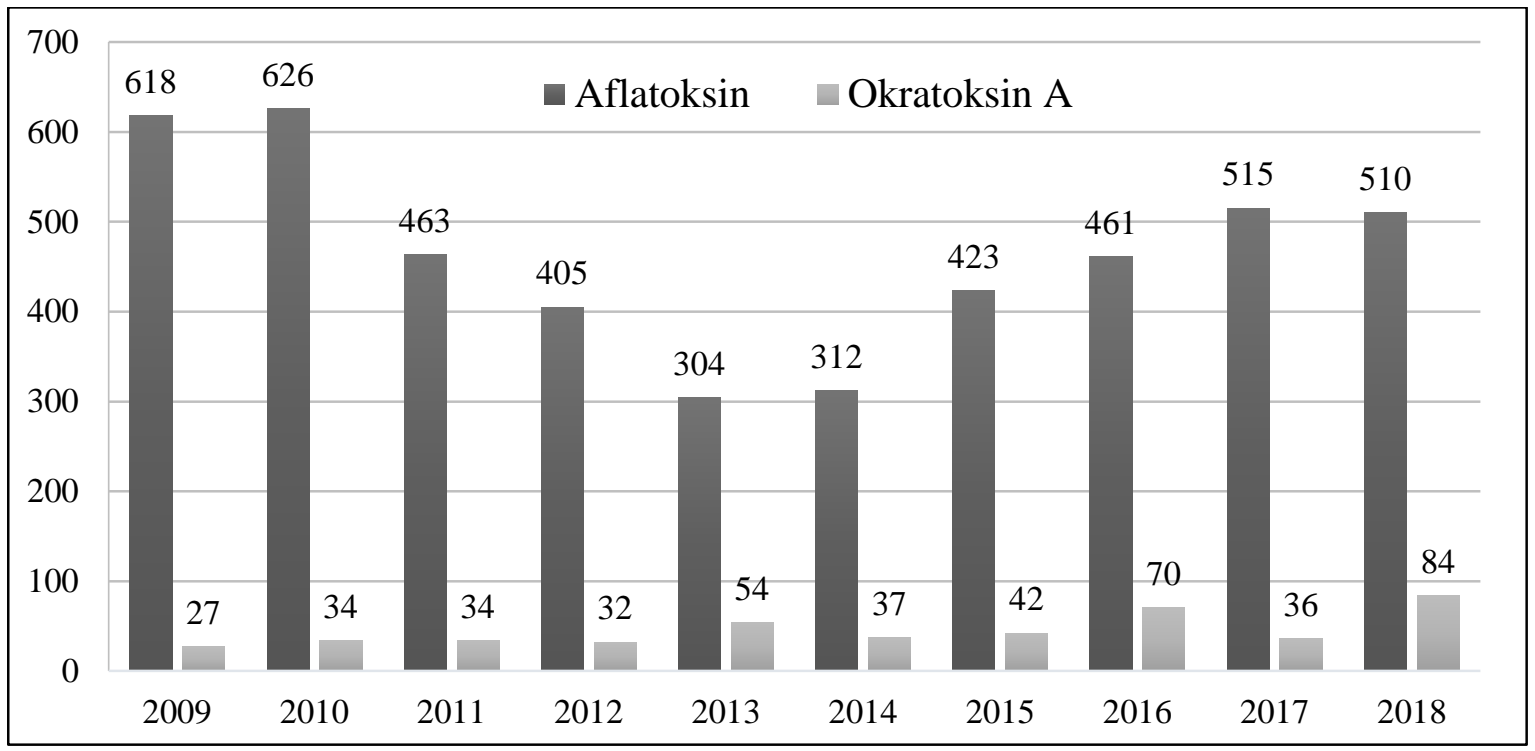

Şekil 5. Gıdalarda 2009-2018 yılları arasında RASFF portalında yapılan aflatoksin ve okratoksin A bildirim sayis 1

Figure 5. RASFF notifications between 2009-2018 on aflatoxin and ocbratoxin A detected in foods

Aflatoksinler ile kontaminasyon riski bulunan belirli gida maddelerinin belirli üçüncü ülkelerden ithalatını düzenleyen özel koşulları uygulamaya koyan ve 1152/2009 sayll Yönetmeliği yürürlükten kaldıran Avrupa Birliği Komisyonu 884/2014 sayılı Yönetmeliği 13 Ağustos 2014 tarihinde yürürlüğe girmiştir. $\mathrm{Bu}$ gida maddelerinin serbest dolaşımına izin verilinceye kadar her bir sevkiyat ile birlikte sağlık sertifikası, numune alma ve analiz sonuçları ve ortak giriş belgesi (Common Entry Document; CED) bulundurma zorunluluğu getirilmiştir (Anonymous, 2014). Bu getirilen yeni yönetmelikle birlikte daha etkin denetimlerin yapıldığ1 speküle edilebilir. Dolayısıyla bu durumun da, 2014'ten sonraki süreçte RASFF bildirimlerinde artışa neden olduğu (Şekil 1, Şekil 4 ve Şekil 5) ve ağın daha verimli kullanıldığını göstermektedir.

Gidalarda 2009-2018 y1llar1 arasinda RASFF portalında yapilan OTA bildirimlerinin yllara göre dağılımı Şekil 5'te verilmiştir. Son on yılda gıdalarda toplamda 450 OTA tespiti yapılmış olup, bu değer toplam mikotoksinlerin \%9'unu oluşturmaktadır. Her ne kadar OTA bildirim sayıları yıllar içerisinde değişim göstermiş olsa da, AF bildirimleri ile kıyaslandığında oldukça düşük bulunmuştur. Çalışmanın kapsadığı dönemde (2009-2018) gidalarda tespit edilen mikotoksin bildirimlerinin \%2'lik kısmını oluşturan Fumonisin, Deoksinivalenol, Zearalenon bildirim sayllar1 ise sirasiyla; 38, 56, 9 olarak tespit edilmiştir. Bu anılan mikotoksinlerin AF ve OTA bildirimlerine oranla çok düşük seviyede olması nedeniyle yıllara göre dağılımı çalışmada kapsam dişı tutulmuştur.

Ülkemiz kaynaklı gidalarda yapilan bildirimler tehlike kategorilerine göre değerlendirildiğinde ise, mikotoksinlerin toplam bildirimlerin yaklaşı $\% 50$ 'sini oluşturduğu tespit edilmiştir. $\mathrm{Bu}$ bağlamda, Türkiye kaynaklı gidalarda öne çıkan iki mikotoksin grubu (AF ve OTA) için yıllara göre yapılan RASFF bildirim sayıları Şekil 6'da sunulmuştur. Anılan periyotta Türkiye kaynaklı g1dalarda toplamda 1236 bildirimde AF tespiti yapılmıştır. En yüksek AF bildirimi (174 bildirim) 
2009 yllında, en düşük AF bildirimi (87 bildirim) ise 2014 yllinda rapor edilmiştir. 2014 yllından sonra AF bildiriminde genel olarak yıldan yıla artış gözlenmiştir. Araştırmanın yapıldı̆̆1 dönemde
Türkiye kaynaklı g1dalarda toplam 132 bildirimde OTA tespiti yapılmıştır. En çok OTA bildirimi (43 bildirim) 2018 yllında görülmektedir (Şekil 6).

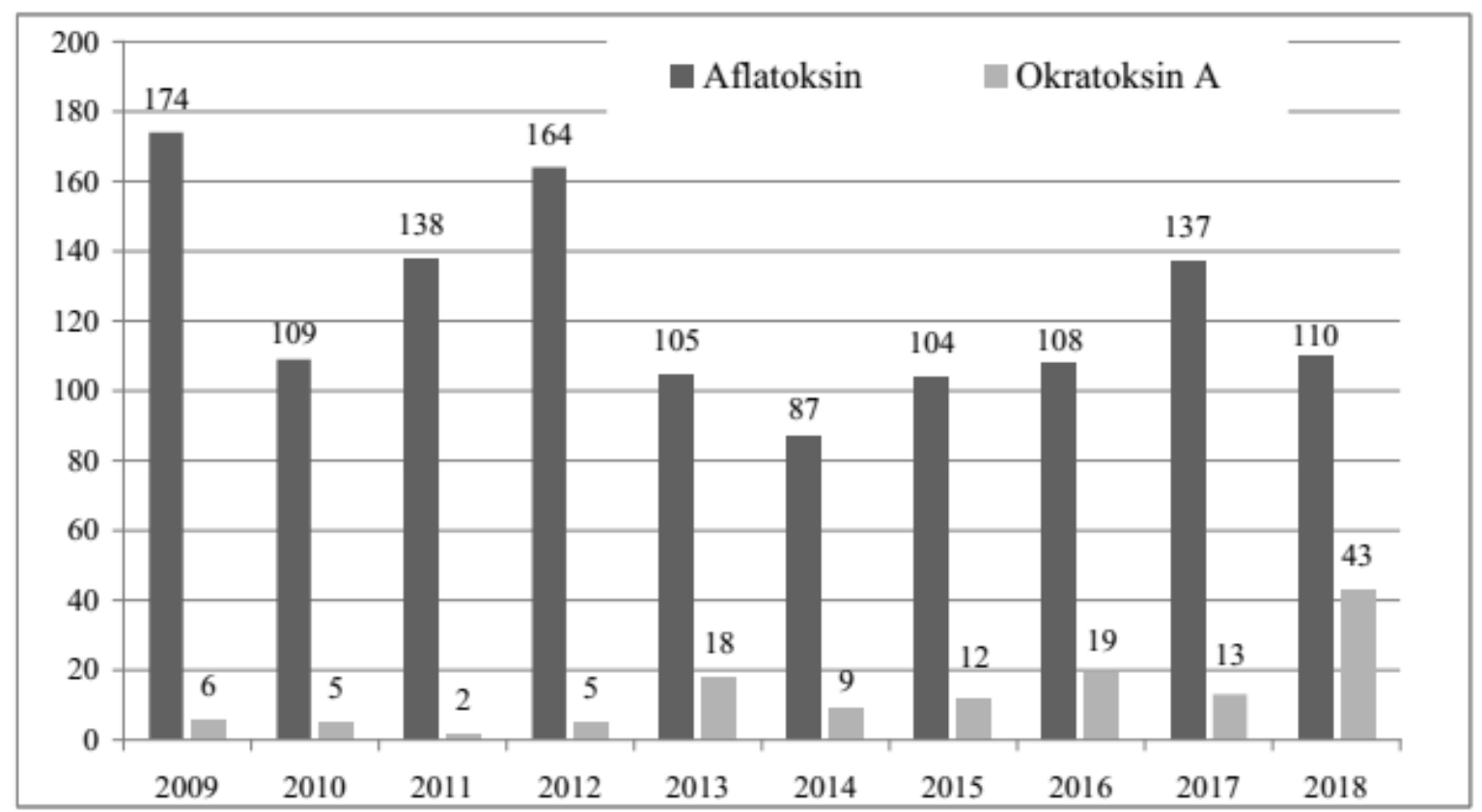

Şekil 6. Türkiye kaynaklı gidalarda 2009-2018 yılları arasında tespit edilen aflatoksin ve okratoksin A RASFF bildirim sayis1

Figure 6. RASFF notifications on aflatoxin and ochratoxin A detected in foods originated from Turkey between 20092018

Kayabaşı (2015) Avrupa Birliği'ne ihraç ettiğimiz ve aflatoksin sorunu yaşadığımız findık, Antep fistığ1 ve kuru incir ile ilişkili olarak numune alma sıklıklarının yıllar içerisindeki değişimine dikkat çekmiştir. Kayabaş1 araştırmasında, 1152/2009 sayll Tüzük ile 2009 yllında belirlenen numune alma sıklıklarının findıkta \% 5'ten \% 10'a, Antep fistığında \% 10'dan \% 50'ye, kuru incirde ise \% 10'dan \% 20'ye çıkarıldığını, 884/2014 sayılı Tüzük ile 2014 yllında ise findikta numune alma sıklığının \% 10'dan rastgeleye çekildiğini rapor etmiştir. İlgili Tüzüğe (884/2014) göre ithalat noktasındaki yetkili otorite, herhangi bir gidanin Birlik içerisinde serbest dolaşımına izin vermeden önce, AF $B_{1}$ ve TAF için numune alarak, Tüzügün ekinde (Ek I) belirtilen sıklıkta kimlik kontrolü ve fiziksel denetim gerçekleştirmektedir. Dolayısıyla bu durum, 2014 y1lindan günümüze aflotoksin bildirimlerinde gerçekleşen artışın önemli bir göstergesidir.
Diğer taraftan, Aspergillus flavus ve Aspergillus parasiticus küfleri belirli gida ve yemlerde uygun sıcaklık ve nem koşulları altında büyüyebildiği, hasat öncesi ve/veya sirasinda, ambalajlama, sevkiyat ve depolama koşullarında aflatoksin ürettiği bilinmektedir (Bushby ve Wogan, 1979). $\mathrm{Bu}$ bağlamda, hasat öncesi ve/veya sirasinda sıcaklık ve nem miktarları aflatoksin oluşumunda büyük önem arz etmektedir. Dolayısıyla, T.C. Tarım ve Orman Bakanlığı Meteoroloji Genel Müdürlüğü resmi web sayfasindan (Anonymous, 2020) 2009-2018 yılları arasındaki Türkiye yıllık toplam yağış verisi alınmış ve ülkemiz kaynaklı gidalarda yapilan toplam mikotoksin bildirimleri ile arasındaki korelasyon incelenmiştir. Buna göre, yılllk toplam yağış $\times$ toplam mikotoksin bildirimi arasında orta düzeyde korelasyon $(r=0.44)$ tespit edilmiștir. Ayrıca, 2009-2018 yılları arasındaki Türkiye ylllk ortalama nisbi nem verisi (Anonymous, 2020) ile ülkemiz kaynaklı gidalarda 
yapilan toplam mikotoksin bildirimleri arasinda zayıf düzeyde korelasyon $(r=0.33)$ saptanmıştır. Türkiye yillik ortalama sicaklik verisi ile kıyaslandığında ise negatif yönlü zayıf düzeyde $(r$ $=-0.30)$ korelasyon bulunmuştur.

\section{SONUÇ}

Bu çalışmada, Gıda ve Yemler için Hızlı Alarm Sistemi (RASFF) veri kaynağ kullanılarak 1 Ocak 2009-31 Aralık 2018 tarihlerini kapsayan on ylllık süreçte RASFF üye ülkeleri ile Türkiye kaynaklı gıda ve gıda ürünlerinde gerçekleşen bildirimler detaylı olarak incelenmiştir. Türkiye kaynaklı gıdalarda yapılan bildirim sayıları ile RASFF üyesi ülkeler tarafından yapılan bildirim sayılarının yıllara göre dağılımı incelendiğinde, bu iki değişken arasında yüksek düzeyde korelasyon $(r=$ $0.71)$ tespit edilmiştir. Diğer taraftan, ilgili süreçte RASFF portalında yapilan toplam bildirimlerin yaklaşık \%9.6'sının ülkemiz kaynaklı olduğu belirlenmiştir. Ürün kategorilerine göre bildirim sayıları değerlendirildiğinde en fazla bildirim meyve ve sebzelerde (\%20) olurken; Türkiye kaynaklı gıdalarda yapılan bildirimlerde de sıralama değişmemiş, en fazla bildirim \%62'lik oranla meyve ve sebzelerde tespit edilmiştir. Tehlike kategorisine göre gidalarda en fazla RASFF bildiriminin mikotoksin kaynaklı olduğu, ülkemiz ihracatında da en önemli sorunun mikotoksin kaynaklı gidaların oluşturduğu saptanmıştır. Bu çalışma kapsamında, RASFF üye ülkeleri tarafından bildirilen toplam mikotoksin değerinin yaklaşık \%26.6'sının Türkiye kaynaklı olduğu belirlenmiş ve veriler arasında orta düzeyde korelasyon $(r=0.45)$ tespit edilmiştir. Hem RASFF üye ülkeleri hem de ülkemiz ihracat1 açısından en önemli tehlike kategorisini aflatoksin oluşturmaktadır. Mikotoksinlerin üremesinde ve çoğalmasında başta sıcaklık ve nem olmak üzere, hasat öncesi ve/veya sırasındaki yağış, depolama veya sevkiyat koşulları gibi birçok faktörün etkili olduğu bilinmektedir. Bu hususta 2009-2018 yılları arasındaki ülkemiz kaynaklı gıdalarda yapilan toplam mikotoksin bildirimleri ile yıllık toplam yağış, yılllk ortalama nisbi nem ve y1llık ortalama sıcaklık verileri kıyaslanmış ve genel olarak orta/zaylf düzeyde korelasyon tespit edilmiştir.
Elde edilen bulgular genel olarak değerlendirildiğinde, son yillarda özellikle mikotoksin bildirimlerindeki artışa paralel olarak RASFF sisteminde g1dalarda yapilan toplam bildirim sayısının arttığı belirlenmiştir. $\mathrm{Bu}$ bağlamda, Türkiye kaynaklı özellikle meyve ve sebzeler ile sert kabuklu yemişler ve tohumlarda aflatoksin bildirimleri maalesef önemli bir yer tutmaktadır. Türkiye kaynaklı gidalarda, 20092018 yılları arasında yapilan bildirimlerin \%80'inin sınır reddi edildiği dikkate alındığında, bu durum ülkemiz ihracatına ekonomik bağlamda zarar vermesinin yanı sıra gıda ürünlerimizin dış pazarda önemli düzeyde itibar kaybetmesine de neden olmaktadır. Eğer diş pazarda rekabet gücümüzü arttırmak istiyorsak, üretimden depolamaya, ambalajlamadan sevkiyata kadar her bir noktada, iyi tarım uygulamaları, üreticilerin bilinçlenmesine yönelik eğitimlerin düzenlenmesi, depolama koşullarının gıda ürünlerine uygun olarak iyileştirilmesi ve denetimlerin artırılması büyük önem taşımaktadır.

\section{ÇIKAR ÇATIŞMASI BEYANI}

Yazarlar, çıkar çatışması olmadığını beyan eder.

\section{YAZAR KATKILARI}

AS, makalenin metodoloji, biçimsel analiz, yazma-orijinal taslak ve görselleştirmesine katkı sunmuştur. MTM, kavramsallaştırma, metodoloji, biçimsel analiz, istatistiksel analiz, yazma- orijinal taslak, yazma-inceleme ve düzenleme, görselleştirme ve danışman olarak katkı sağlamıştır. Yazarlar makalenin son halini okudu ve onayladi.

\section{KAYNAKLAR}

Anonymous (2007). The Rapid Alert System for Food and Feed (RASFF) Annual Report 2007. https://ec.europa.eu/food/sites/food/files/safe ty/docs/rasff_annual_report_2007_en.pdf,

(Accessed: 06 May 2019).

Anonymous (2011). Bitkisel Gida ve Yemin İhracatında Sağlık Sertifikası Düzenlenmesi ve İhracattan Geri Dönen Ürünler İçin Uygulama Yönetmeliği. G1da, Tarım ve Hayvancillk Bakanlığ1. 25 Kasım 2011 tarih ve 28123 sayll Resmî Gazete, Ankara. 
Anonymous (2014). Commission Implementing Regulation (EU) No 884/2014 of 13 August 2014 imposing special conditions governing the import of certain feed and food from certain third countries due to contamination risk by aflatoxins and repealing Regulation (EC) No 1152/2009 Text with EEA relevance.

Anonymous (2017). The Rapid Alert System for Food and Feed (RASFF) Annual Report 2017. https://ec.europa.eu/food/sites/food/files/safe ty/docs/rasff_annual_report_2017.pdf,

(Accessed: 06 May 2019).

Anonymous (2020). T.C. Tarrm ve Orman Bakanlığı Meteoroloji Genel Müdürlüğü. Türkiye yıllık toplam yağış verisi, Türkiye yılllk ortalama nisbi nem verisi, Türkiye y1llık ortalama sicaklık verisi. www.mgm.gov.tr/veridegerlendirme/ilve-ilceler-

istatistik.aspx?k=parametrelerin'TurkiyeAnalizi (Erişim tarihi: 03.06.2020).

Bánáti, D. (2011). Consumer response to food scandals and scares. Trends Food Sci Tech, 22, 5660.

Bushby, W.F., Wogan, G.N., 1979. Food-borne mycotoxins and alimentary mycotoxicoses. (In $\mathrm{H}$. Riemann \& F. L. Bryan, Editör). In: Food-borne infections and intoxication. Academic Press, 519610, New York.

Çınar, S., Yılmaz, S.N., Aydın, E., Yorulmaz, A. (2016). Gıda ve Yem İçin Hızlı Alarm Sistemi (RASFF) 2009-2016 Türkiye Raporu. Türk Tarm - Gida Bilim Teknol. Derg., 5(8): 873-882.

European Commission (2011). Commission Regulation (EU) No 16/2011 of 10 January 2011 laying down implementing measures for the Rapid alert system for food and feed. Official Journal of the European Union, L6, 7-10.

Koşar, A. (2018). Türkiye'nin son on yllda en çok ihracat ve ithalat yaptı̆̆1 ülkelerin hiyerarşik kümeleme analizi ile gruplandırilmasi ve değerlendirilmesi. Bucak Ișletme Fakültesi Dergisi, 1(1): 17-28.

Kowalska, A., Soon, J.M., Manning, L. (2018). A study on adulteration in cereals and bakery products from Poland including a review of definitions. Food Control, 92: 348-356.

Marvin, H.J.P., Kleter, G.A., Prandini, A., Dekkers, S., Bolton, D.J. (2009). Early identification systems for emerging foodborne hazards. Food Chem Toxicol, 47, 915-926.

Pigłowski, M. (2020). Food hazards on the European Union market: The data analysis of the Rapid Alert System for Food and Feed. Food Sci Nutr, 8, 1603-1627.

Pop, C., Frunză, G., Ştef, D. S., Mărculet, A.P. (2015). Study on food safety through RASFF notifications in case of contamination with mycotoxins. Univ Agric Sci Vet Med iasi, 64: 166172.

RASFF Portal (2019). The Rapid Alert System for Food and Feed (RASFF) Portal Search Page. https://webgate.ec.europa.eu/rasffwindow/portal/ (Accessed: 06 May 2019).

Spichtinger, D., Astley, S. (2009). Report from the first international MoniQA conference: Increasing trust in rapid analysis for food quality and safety. Qual Assur Saf Crop, 1, 61-64.

Trevisani, M., Rosmini, R. (2008). Duties and functions of veterinary public health for the management of food safety: Present needs and evaluation of efficiency. Vet Res Commun, 32, 2532.

Yilmaz Çebi, S., Olhan, E. (2017). Avrupa Birliği Gida ve Yemde Hizlı Alarm Sistemi'nin Türkiye'nin gıda ürünleri ihracat1 üzerine etkilerinin değerlendirilmesi. Tarm Ekonomisi Dergisi, 23(1) 133-144. 